\title{
ACAROLOGY
}

\section{Distribuição Espacial de Ácaros Fitófagos (Acari: Tetranychidae) em Morangueiro}

\author{
Marcos A.M. Fadini ${ }^{1}$, Hamilton G. Oliveira ${ }^{2}$, Madelaine Venzon ${ }^{1}$, Angelo Pallini ${ }^{2}$ e \\ EVALDO F. VILELA ${ }^{2}$ \\ ${ }^{1}$ Empresa de Pesquisa Agropecuária de Minas Gerais - EPAMIG, Vila Gianetti 46, 36570-000, Viçosa, MG \\ fadini@epamig.br \\ 2Depto. Biologia Animal, Univ. Federal de Viçosa, 36570-000, Viçosa, MG, pallini@ufv.br
}

Neotropical Entomology 36(5):783-789 (2007)

\author{
Spatial Distribution of Phytophagous Mites (Acari: Tetranychidae) on Strawberry Plants
}

\begin{abstract}
Many phytophagous mites can attack strawberry plants, Fragaria x ananassa, among them the southern red mite, Oligonychus ilicis McGregor, and the two-spotted spider mite, Tetranychus urticae Koch. They are found together feeding on the same plant on the upper and underside of the leaves, respectively. Here we studied the choice for feeding sites of O. ilicis and T. urticae on strawberry plants. The first hypothesis tested whether the feeding site choice would be related to the fitness of the species. The second hypothesis dealt whether the feeding site would be determined by the presence of a heterospecific mite. We evaluated the preference, biology and reproductive success of $O$. ilicis and $T$. urticae on the under and upper side surface of strawberry leaves infested or not by the heterospecific. $O$. ilicis preferred to stay on the upper side surface while T. urticae preferred the underside. The preference for the leaf surface correlated with the reproductive success of the species (measured by the intrinsic growth rate). The choice pattern of feeding sites did not alter when the choice test was applied using sites previously infested by heterospecific. Although $O$. ilicis and T. urticae, apparently, do not interact directly for feeding sites, there is a chance that the first species induces defenses in strawberry plant enabling to reduce the fitness of the second species. The possibility of those species stay together on strawberry plant increases the damage capacity to the culture.
\end{abstract}

KEY WORDS: Herbivory, interespecifc interaction, food web, Tetranychus urticae, Oligonychus ilicis, Fragaria

RESUMO - O morangueiro, Fragaria $\mathrm{x}$ ananassa, pode ser atacado por diferentes espécies de ácaros fitófagos, dentre elas o ácaro-vermelho, Oligonychus ilicis McGregor, e o ácaro-rajado, Tetranychus urticae Kock. Essas espécies são encontradas juntas, alimentando-se, com maior freqüência, sobre a epiderme adaxial e abaxial das folhas, respectivamente. Neste trabalho estudou-se o padrão de escolha de $O$. ilicis e T. urticae por sítio de alimentação em plantas de morangueiro. Duas hipóteses foram formuladas: a primeira, que a escolha por sítios de alimentação estaria relacionada à aptidão das espécies; a segunda, que esta escolha seria determinada pela presença do heteroespecífico. Com o objetivo de testar tais hipóteses, avaliou-se a preferência, biologia e sucesso reprodutivo de O. ilicis e T. urticae sobre a face abaxial e adaxial de folhas de morangueiro infestadas ou não pelo heteroespecífico. O. ilicis preferiu permanecer sobre a face adaxial enquanto T. urticae preferiu permanecer sobre a face abaxial de folhas de morangueiro. A preferência pelas faces foliares correlacionou-se com o sucesso reprodutivo das espécies, avaliado pela taxa intrínseca de crescimento populacional $\left(\mathrm{r}_{\mathrm{m}}\right)$. $\mathrm{O}$ padrão de escolha não se alterou quando as espécies foram submetidas ao teste de escolha entre as faces foliares previamente infestadas pelo heteroespecífico. É discutida a possibilidade de T. urticae induzir defesas da planta capazes de reduzir a aptidão de $O$. ilicis e vice-versa. A possibilidade dessas espécies permanecerem juntas sobre plantas de morangueiro aumenta a capacidade de dano à cultura.

PALAVRAS-CHAVE: Herbivoria, interação interespecífica, teia alimentar, Tetranychus urticae,

Oligonychus ilicis, Fragaria 
A distribuição espacial de espécies fitófagas sobre plantas pode ser determinada por interações interespecíficas (Lawton \& Strong 1981). Tais interações podem ser diretas, quando uma espécie atua sobre outra sem uma espécie intermediária. Ou indiretas, quando a interação entre espécies é mediada pela planta, através da alteração da qualidade nutricional, da fisiologia, da morfologia e do crescimento dos tecidos atacados na planta co-ocupada (Janssen et al. 1998, Inbar et al. 1999a, b)

Apesar de a ocorrência simultânea de diferentes espécies de ácaros fitófagos sobre plantas ter sido relatada há décadas (Foott 1962, 1963), é pequeno o número de estudos que investiga as interações entre ácaros fitófagos heteroespecíficos e suas conseqüências na distribuição espacial desses fitófagos sobre as plantas (Shiojiri et al. 2002, Dorn et al. 2003).

O morangueiro, Fragaria x ananassa, pode ser atacado por diferentes espécies de ácaros. Dentre elas, o ácarorajado, Tetranychus urticae Kock, é praga primária. Em altas densidades, essa espécie diminui a taxa fotossintética das plantas reduzindo o número e o peso dos frutos (Chiavegato \& Mischan 1981). O ácaro-vermelho, Oligonychus ilicis McGregor, apesar de não ser relatado como praga primária, também tem sido observado provocando injúrias em plantas de morango em cultivo protegido e em sistema de produção orgânica (obs. pes.).

Para caracterizar o modo de vida das espécies da família Tetranychidae, Saitô (1983) utilizou critérios como estrutura e densidade da teia, sítio de oviposição, tipo de cobertura para os ovos e sítio preferido de alimentar e defecação. Seguindo tais critérios, as espécies do gênero Tetranychus são classificadas como ácaros que constroem teias irregulares e complicadas nas folhas da planta hospedeira e acumulam fezes e ovos no emaranhado das teias (Saitô 1985). No gênero Oligonychus, o modo de vida das espécies depende da planta hospedeira (Saitô 1985).

Em morangueiro, O. ilicis e T. urticae são encontrados e se alimentam com maior freqüência sobre a epiderme adaxial e abaxial das folhas, respectivamente. Os sítios de oviposição e de deposição de fezes correspondem aos sítios de alimentação, podendo ser simultâneo o ataque dessas espécies ao morangueiro (obs. pes.). Dessa forma, apesar de explorarem recursos alimentares similares, ou seja, a epiderme foliar, O. ilicis e T. urticae são capazes de permanecer sobre o morangueiro sem, aparentemente, interagirem por alimento e espaço. A escolha por sítios de alimentação diferentes, por espécies de nichos semelhantes, como $O$. ilicis e $T$. urticae, pode ser uma forma de evitar interação direta por recursos (e.g. alimento, espaço, refúgio etc.) (Morris 2003).

Como exemplo de espécies de fitófagos que têm comportamentos para evitar interação direta por recursos, a mosca branca, Bemisia argentifolii Bellows \& Perring, que é sugadora da seiva do floema, alimenta-se com maior freqüência sobre a face abaxial de tomateiro. Enquanto que a mosca minadora, Liriomyza trifolii (Burgess), que ocorre junta a $B$. argentifolii, alimenta-se construindo minas sobre a face adaxial de folhas de tomateiro. As duas espécies de fitófagos têm a mobilidade das fases imaturas limitadas. As ninfas de $B$. argentifolii são estacionárias, com movimentação limitada ao primeiro instar, enquanto que as larvas de $L$. trifolii têm a mobilidade restrita às minas, o que reduz a probabilidade de interação direta entre esses fitófagos nas folhas de tomateiro (Parrella 1987). Tais comportamentos podem reduzir a probabilidade de interação direta entre essas espécies fitófagas.

Para investigar a possibilidade de interação direta entre $O$. ilicis e $T$. urticae sobre morangueiro, estudou-se o padrão de escolha de $O$. ilicis e $T$. urticae por sítios de alimentação na planta. Duas hipóteses foram formuladas: a primeira seria que a escolha por sítios de alimentação estaria relacionada à aptidão das espécies. A segunda hipótese seria que a escolha por sítios de alimentação seria determinada pela presença do heteroespecífico. Com o objetivo de testar tais hipóteses avaliou-se a preferência, a biologia e o sucesso reprodutivo de $O$. ilicis e $T$. urticae sobre as duas faces das folhas de morangueiro infestadas ou não pelo heteroespecífico.

\section{Material e Métodos}

Criações estoque. Adultos de $O$. ilicis e $T$. urticae foram coletados em morangueiro, cultivar 'IAC Campinas', em casa de vegetação e transferidos para laboratório de Acarologia da Universidade Federal de Viçosa, MG, visando obter as progênies a serem utilizadas no estudo. Em média, dez casais de $O$. ilicis e $T$. urticae foram criados sobre a face abaxial e adaxial, respectivamente. de discos foliares de morangueiro (30 mm Ø) da cultivar 'IAC Campinas'. Os discos foram colocados para flutuar, individualmente, em caixas do tipo $\operatorname{Gerbox}^{\circledR}(3,5 \times 11,5 \times 11,5 \mathrm{~cm})$ contendo água. No centro de cada disco foi feito um pequeno orifício para passagem de um alfinete entomológico fixado no fundo da caixa por meio de cola de silicone. Desta forma, os discos permaneceram imóveis, sem tocar na parede da caixa, deslocando-se, somente, para cima e para baixo conforme o nível da água (Reis \& Alves 1997). As caixas foram mantidas em câmara climatizada, tipo $\mathrm{BOD}$, à temperatura de $25^{\circ} \mathrm{C}$, umidade relativa de $70 \pm 10 \%$ e fotofase de $14 \mathrm{~h}$.

Preferência de $\boldsymbol{O}$. ilicis e $T$. urticae pela face adaxial ou abaxial de folhas de morangueiro. Para o estudo da preferência de $O$. ilicis e $T$. urticae pela face adaxial ou abaxial de folhas, foram recortados 80 discos $(13 \mathrm{~mm} \varnothing)$ de folhas de morangueiro, cultivar 'IAC Campinas'. Os discos foram cortados ao meio e colados, por meio de fita plástica adesiva, com faces invertidas, de forma que tanto a face abaxial quanto a face adaxial estavam presentes em ambos os lados do disco. Posteriormente, os discos foram colocados, individualmente, em placas de Petri de plástico (35 mm Ø; $15 \mathrm{~mm}$ altura). Para fixar os discos às placas, preparou-se solução de carragenina ( $2 \mathrm{~g} / 100 \mathrm{ml}$ de água) aquecida durante $60 \mathrm{seg}$. em forno de microondas. A solução de carragenina foi vertida no interior de 80 placas de Petri até formar uma camada de espessura aproximada de $5 \mathrm{~mm}$. Os discos foram colocados sobre a solução antes que ela solidificasse. Foi retirado o excesso de carragenina ao redor dos discos foliares, preenchendo-se o espaço formado com água. Tal procedimento impediu que os ácaros saíssem dos discos foliares.

No centro de cada disco foi fixado um alfinete entomológico que serviu como base para a liberação de um indivíduo de $O$. 
ilicis ou de T. urticae. Após $24 \mathrm{~h}$ da liberação, foi registrada a face em que o indivíduo havia permanecido. Durante o experimento as placas de Petri foram mantidas em câmara climatizada, tipo BOD, à temperatura de $25^{\circ} \mathrm{C}$, umidade relativa de $70 \pm 10 \%$ e fotofase de $14 \mathrm{~h}$. Para avaliar a preferência de $O$. ilicis e T. urticae às faces abaxial e adaxial de morangueiro utilizou-se o teste binomial (Siegel \& Castellan 1988).

Biologia de $\boldsymbol{O}$. ilicis e $T$. urticae sobre a face adaxial e abaxial de folhas de morangueiro. Para o estudo de $O$. ilicis e T. urticae foram recortados 80 discos $(13 \mathrm{~mm} \varnothing)$ de folhas de morangueiro, cultivar 'IAC Campinas'. Os discos foram colocados, individualmente, em placas de Petri de plástico (35 $\mathrm{mm} \mathrm{Ø;15} \mathrm{mm}$ altura), conforme procedimento descrito no experimento anterior. Quarenta discos foliares foram colocados com a face adaxial para cima e outros 40 discos foram colocados com a face abaxial para cima.

Colocaram-se, em cada disco foliar, dois ovos de um dia de idade de $O$. ilicis ou de T. urticae. Após a eclosão da primeira larva, retirou-se o ovo remanescente. $\mathrm{O}$ acompanhamento do desenvolvimento da fase imatura foi realizado duas vezes ao dia, no período da manhã e da tarde, para registrar a duração do desenvolvimento das fases imaturas dos ácaros. As fases observadas durante o estudo foram ovo, larva, proto-crisálida, proto-ninfa, deuto-crisálida, deuto-ninfa, telo-crisálida e adulto. Quantificou-se a produção diária de ovos e a sobrevivência de fêmeas adultas sobre os mesmos discos foliares utilizados para a biologia das fases imaturas.

A duração média das fases imaturas de $O$. ilicis e $T$. urticae mantidas sobre face abaxial e adaxial de folhas de morangueiro foi comparada pelo teste de "Mann-Whitney" a 5\% de probabilidade (Sokal \& Rohlf 1995). As análises de sobrevivência foram realizadas através do teste de "KaplanMeier - Long Rank Test" a 5\% de probabilidade (Hosmer \& Lemeshow 1999).

Para o estudo do sucesso reprodutivo utilizou-se a taxa intrínseca de crescimento populacional $\left(\mathrm{r}_{\mathrm{m}}\right)$. Essa taxa considera parâmetros de reprodução e sobrevivência para avaliar o sucesso reprodutivo das populações em diferentes condições bióticas e abióticas. Para o cálculo da $r_{m}$ foi utilizada a equação de Lotka (Carey 1993):

$$
\sum_{x=0}^{T} 1_{x} m_{x} e^{-r_{m}(x+1)}=1
$$

Onde, $\mathrm{x}=$ intervalo de tempo; $\mathrm{T}=$ classe etária mais velha; $1_{x}=$ taxa de sobrevivência durante o estágio $\mathrm{x} ; \mathrm{m}_{\mathrm{x}}=$ número de descendentes fêmeas produzidas no estágio $x$.

Os valores de $r$ foram comparados pelo teste de "MannWhitney", a 5\% de probabilidade, a partir da variância gerada pelo método de Jackknife (Sokal \& Rholf 1995). Nesse método, recalcularam-se os valores de $r$ retirando uma repetição (= fêmea) por vez, o que possibilitou verificar quanto cada repetição contribuiu na variância total do experimento, gerando-se uma média e um erro padrão associado (Maia et al. 2000).

Preferência de $\boldsymbol{O}$. ilicis e $\boldsymbol{T}$. urticae pela face adaxial ou abaxial de folhas de morangueiro previamente infestadas pelo heteroespecífico. Para avaliar a preferência de $O$. ilicis e T. urticae entre face abaxial ou face adaxial, previamente infestadas com o ácaro, foram recortados 80 discos $(13 \mathrm{~mm}$ $\varnothing)$ de folhas de morangueiro, cultivar 'IAC Campinas'. Os discos foram preparados, acondicionados e individualizados em placas de Petri conforme procedimento descrito no primeiro experimento.

Para pré-infestação, foram colocados cinco adultos de T. urticae na metade adaxial em 40 discos foliares e, nos 40 discos restantes foram adicionados cinco adultos de $O$. ilicis na metade abaxial. O procedimento permitiu que ovos, fezes e teias fossem depositados sobre as faces pré-infestadas. Para evitar que os adultos passassem para a metade ao lado, uma camada de algodão úmido foi colocada sobre ela. Após $24 \mathrm{~h}$, os adultos do heteroespecífico e o algodão úmido foram retirados. No centro de cada disco foi fixado um alfinete entomológico que serviu como base para a liberação das fêmeas de $O$. ilicis ou T. urticae. Após $24 \mathrm{~h}$ da liberação foi registrada a face em que as fêmeas haviam permanecido. As placas de Petri foram mantidas em câmara climatizada, tipo $\mathrm{BOD}$, à temperatura de $25^{\circ} \mathrm{C}$, umidade relativa de 70 $\pm 10 \%$ e fotofase de $14 \mathrm{~h}$. Para avaliar a preferência de $O$. ilicis e T. urticae às faces abaxial ou adaxial de morangueiro, previamente infestadas pelo heteroespecífico, utilizou-se o teste binomial (Siegel \& Castellan 1988).

\section{Resultados}

Preferência de $\boldsymbol{O}$. ilicis e $\boldsymbol{T}$. urticae pela face adaxial ou abaxial de folhas de morangueiro. Após $24 \mathrm{~h}, 20$ indivíduos de $O$. ilicis e 31 indivíduos de T. urticae foram recuperados sobre os discos foliares. Os indivíduos restantes estavam sobre a água e não foram incluídos no cálculo da preferência. Apesar da perda, o número de indivíduos registrado sobre os discos foliares foi suficiente para realizar o teste binomial de preferência.

Indivíduos de $O$. ilicis preferiram permanecer sobre a face adaxial ( $\mathrm{g} .1 .=19 ; \mathrm{P}=0,037)$, enquanto indivíduos de T. urticae preferiram permanecer sobre face abaxial (g.l. = $30 ; \mathrm{P}=0,001$ ) de folhas de morangueiro (Fig. 1).

Desenvolvimento, sobrevivência e sucesso reprodutivo de $\boldsymbol{O}$. ilicis e $T$. urticae sobre face adaxial e abaxial de

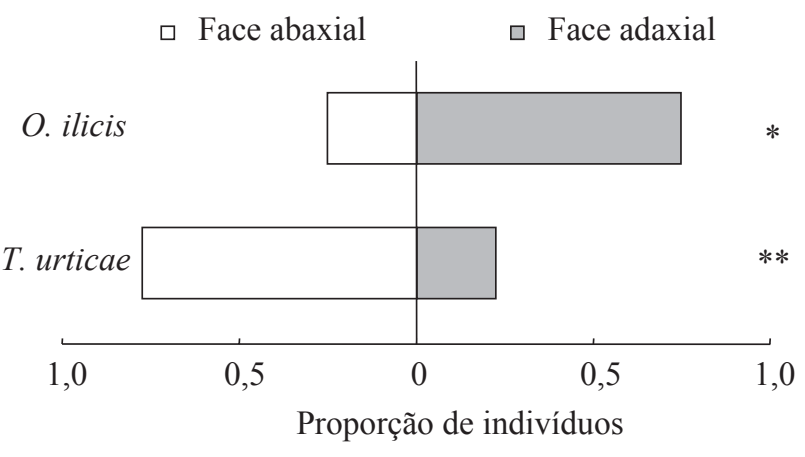

Fig. 1. Proporção de indivíduos de O. ilicis e T. urticae que preferiram a face abaxial ou adaxial de folhas de morangueiro (teste Binomial; ${ }^{*} \mathrm{P}<0,05 ; * * \mathrm{P}<0,01$ ). 
folhas de morangueiro. Com exceção da fase de larva, a duração das fases imaturas de $O$. ilicis não diferiram quando mantidas sobre a face abaxial em relação às mantidas sobre a face adaxial de folhas de morangueiro (Fig. 2). Fato semelhante ocorreu com T. urticae, ou seja, as durações das fases imaturas dessa espécie não diferiram quando mantidas sobre a face abaxial em relação às mantidas sobre a face adaxial (Fig. 3). As curvas de sobrevivência de $O$. ilicis diferiram quando os ácaros foram mantidos sobre a face abaxial em relação aos mantidos sobre a face adaxial de folhas de morangueiro $(\mathrm{KM}=2,62 ; \mathrm{P}=0,008)$. Os indivíduos mantidos sobre a face abaxial apresentaram tempo para morte aproximado de 20 dias, enquanto que aqueles mantidos sobre a face adaxial morreram próximo aos 30 dias (Fig. 4). As curvas de sobrevivência de T. urticae não diferiram entre as faces abaxial e adaxial $(\mathrm{KM}=-1,71$; $\mathrm{P}=0,087)$. Os indivíduos mantidos sobre a face abaxial ou adaxial apresentaram tempo para morte aproximado de 40 dias (Fig. 5).

Os valores da $r_{m}$ para fêmeas de $O$. ilicis diferiram entre as faces foliares de morangueiro. Fêmeas mantidas na face abaxial morreram antes de iniciar a oviposição, impossibilitando o cálculo da $\mathrm{r}_{\mathrm{m}}$, enquanto que, aquelas da face adaxial apresentaram $r_{\mathrm{m}}$ de $0,128 \pm 0,002 \mathrm{dia}^{-1}$. Os valores da $r_{m}$ para as fêmeas de $T$. urticae também diferiram com a face foliar $(Z=3,57 ; P=0,0003)$ (teste de "Mann-Whitney"). As fêmeas mantidas sobre a face abaxial apresentaram $r_{m}$ de $0,205 \pm 0,008 \mathrm{dia}^{-1} \mathrm{e}$ adaxial 0,196 $\pm 0,001 \mathrm{dia}^{-1}$ (Fig. 6).

Preferência de $\boldsymbol{O}$. ilicis e $T$. urticae pela face adaxial ou abaxial de folhas de morangueiro previamente infestadas pelo heteroespecífico. Após $24 \mathrm{~h}, 19$ indivíduos de $O$. ilicis e 29 indivíduos T. urticae foram recuperados sobre os discos foliares. Os indivíduos restantes estavam sobre a água e não foram incluídos no cálculo da preferência. Apesar da perda, o número de indivíduos registrado sobre os discos foliares foi suficiente para realizar o teste binomial de preferência.

Os indivíduos de $O$. ilicis permaneceram sobre face adaxial (g.l. $=18 ; \mathrm{P}=0,007)$ e os $T$. urticae permaneceram sobre face abaxial de folhas de morangueiro (g.l. $=28$; $\mathrm{P}<$ 0,001) (Fig. 7).

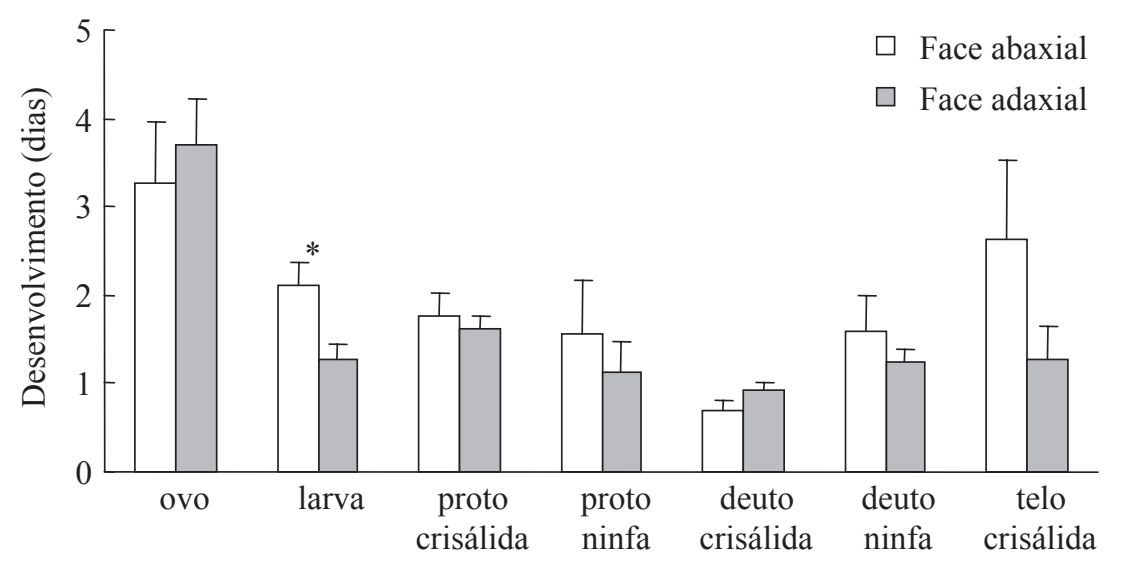

Fig. 2. Duração em dias das fases imaturas de $O$. ilicis mantidas sobre face abaxial e adaxial de folhas de morangueiro (teste de "Mann-Whitney"; *P $<0,05)$.

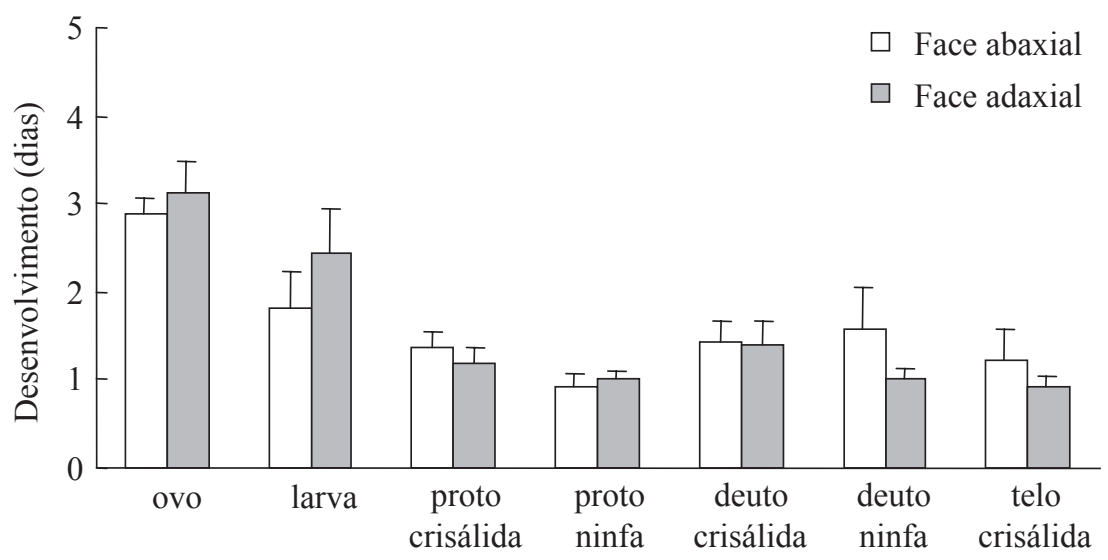

Fig. 3. Duração em dias das fases imaturas de T. urticae mantidas sobre face abaxial e adaxial de folhas de morangueiro (teste de "Mann-Whitney"; *P $<0,05)$. 


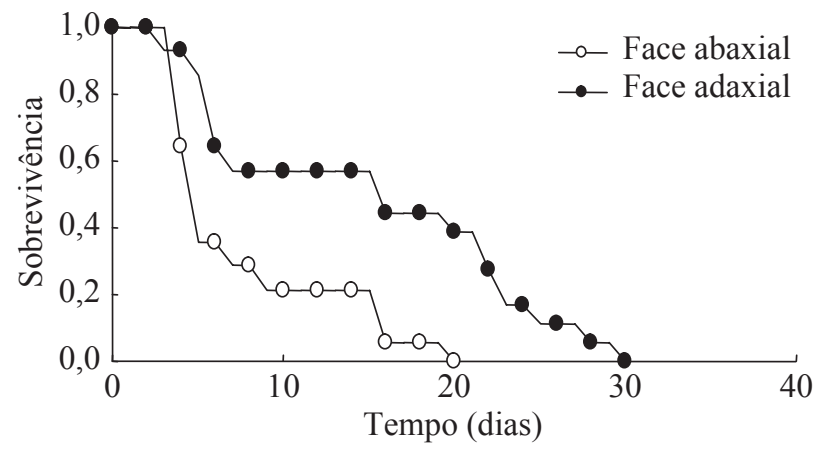

Fig. 4. Curvas de sobrevivência de $O$. ilicis mantidos sobre face abaxial e adaxial de folhas de morangueiro $(\mathrm{KM}=2,62$; $\mathrm{P}=0,008$ ) (teste de "Kaplan-Meier - Long Rank Test").

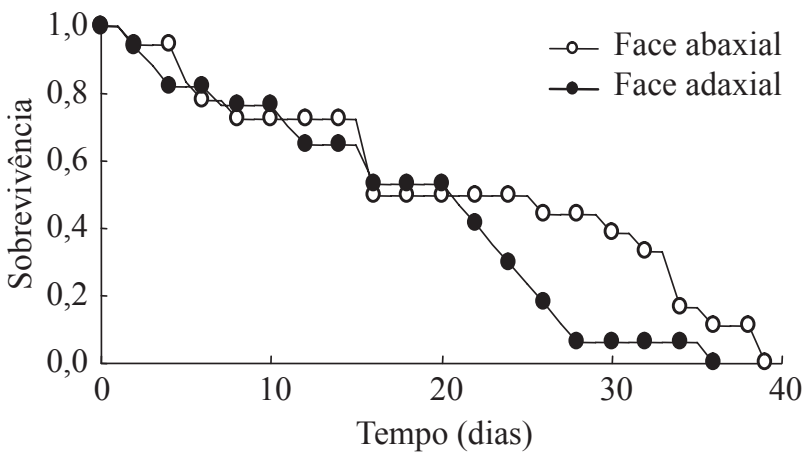

Fig. 5. Curvas de sobrevivência de T. urticae mantidos sobre face abaxial e adaxial de folhas de morangueiro $(\mathrm{KM}=-1,71$; $\mathrm{P}=0,087$ ) (teste de "Kaplan-Meier - Long Rank Test").

\section{Discussão}

O. ilicis e T. urticae são capazes de permanecerem juntos, sobre a mesma planta, mesmo possuindo modos de vida semelhantes e explorando o mesmo recurso alimentar. Possivelmente, este fato está relacionado à escolha de diferentes sítios de alimentação na planta. $O$. ilicis permanece sobre a face adaxial enquanto $T$. urticae permanece sobre a face abaxial de folhas de morangueiro. $O$ fato de se alimentarem de faces diferentes das folhas permite às espécies explorarem, simultaneamente, a mesma fonte de recursos e reduzirem a probabilidade de interação direta.

As faces escolhidas por $O$. ilicis e T. urticae foram aquelas em que as espécies apresentaram maior aptidão, avaliada pela taxa intrínseca de crescimento $\left(\mathrm{r}_{\mathrm{m}}\right)$. Para O. ilicis a maior $\mathrm{r}_{\mathrm{m}}$ foi verificada na fase adaxial, enquanto, para T. urticae, a maior $r_{m}$ foi verificada na face abaxial, correspondendo às faces preferidas pelas espécies. O padrão de escolha não se alterou quando as espécies foram submetidas ao teste de escolha entre as faces foliares previamente infestadas pelo heteroespecífico. Ou seja, as faces preferidas pelas espécies de ácaros continuaram sendo aquelas em que foi verificada a maior $r_{m}$. Tal fato demonstra que a existência de indicativos do heteroespecífico sobre a folha não interfere na escolha do sítio de alimentação dos ácaros. A duração das fases imaturas de $O$. ilicis e $T$. urticae não apresentou diferença significativa com a face foliar. Enquanto a sobrevivência de $O$. ilicis foi maior sobre a face adaxial do que sobre face abaxial, a sobrevivência de T. urticae não se alterou com a face em que os indivíduos foram mantidos.

Apesar da não interferência da pré-infestação sobre a escolha dos sítios de alimentação de $O$. ilicis e $T$. urticae, Foott $(1962,1963)$ relatou que a permanência de espécies de ácaros fitófagos da família Tetranychidae sobre a mesma face foliar é pouco provável. Tais populações não são capazes coexistir por longo período sobre a mesma planta, devido às altas taxas de crescimento populacional e capacidade de ácaros da família Tetranychidae explorarem recursos alimentares até o esgotamento e a extinção local (van Baalen \& Sabelis 1995).

O comportamento relatado neste estudo foi semelhante ao observado por Foott $(1962,1963)$ para Tetranychus telarius Koch e Panonychus ulmi Koch (Acari: Tetranychidae). Essas espécies podem ocorrer juntas sobre plantas de pêra, Pirus sp. Quando isso acontece, T. telarius move-se para a face adaxial das folhas, enquanto $P$. ulmi move-se para a face

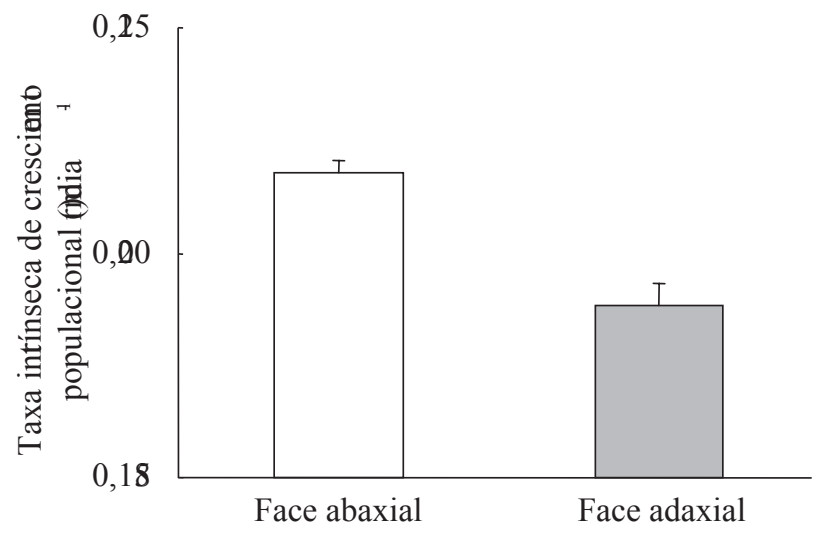

Fig. 6. Taxa intrínseca de crescimento populacional de $T$. urticae sobre face abaxial $\left(\mathrm{r}_{\mathrm{m}}=0,205 \pm 0,008\right.$ dia -1$)$ e adaxial $\left(r_{m}=0,196 \pm 0,001\right.$ dia -1$)$ de morangueiro (teste de "MannWhitney"; $Z=3,57 ; P=0,0003$ ).

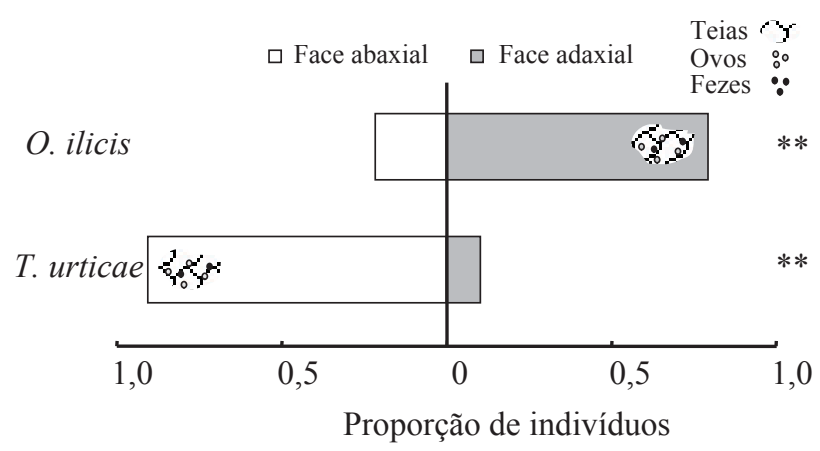

Fig. 7. Proporção de indivíduos de $O$. ilicis e $T$. urticae que preferiram face abaxial ou adaxial de folhas de morangueiro préinfestadas pelo heteroespecífico (teste Binomial; $* * \mathrm{P}<0,01$ ). 
abaxial das folhas. O comportamento diferenciado de escolha das faces retarda, contudo não impede, que a população de P. ulmi seja suprimida por T. telarius. Foott (1963) atribui o fato à capacidade de T. telarius apresentar maior produção de teias, maior fecundidade, desenvolvimento rápido e maior habilidade de causar injúria às folhas em comparação com P. ulmi. Isso mostra que a estratégia de explorar diferentes sítios para alimentação sobre mesma planta é comum em outras espécies de ácaros fitófagos.

Alternativamente, a escolha por sítios de alimentação diferenciados também pode estar relacionada à morfologia do empódio e, conseqüentemente, à capacidade das espécies em fixarem-se nas folhas das plantas hospedeiras (Gutierrez \& Helle 1985). Espécies do gênero Oligonychus têm menor capacidade de se fixar nas folhas da planta hospedeira devido à morfologia do empódio. Desta forma, a maior parte das espécies desse gênero permanece sobre a face adaxial das folhas. As espécies do gênero Tetranychus, por sua vez, têm maior capacidade de se fixar às folhas das plantas hospedeiras (Gutierrez \& Helle 1985).

A competição por recurso foi, no passado, o fator mais usual para explicar a estruturação de comunidades biológicas. Entretanto, Hairston et al. (1960) sugeriram que os fitófagos, em particular, não são sujeitos à competição. Os autores argumentaram que as populações de fitófagos seriam controladas por níveis tróficos superiores (e.g. predadores) e não seriam limitadas por recurso alimentar (i.e., plantas). Esse ponto de vista foi defendido por ecólogos durante longo período (Lawton \& Strong 1981). Entretanto existe a possibilidade teórica de fitófagos competirem indiretamente por recursos alimentares (Agrawal 2005). Com o desenvolvimento de estudos na área de defesa induzida de plantas (Karban \& Baldwin 1997), observou-se que as defesas são sistêmicas, ou seja, translocam pela planta uma vez ativadas. Dessa forma, existe possibilidade de as defesas induzidas por uma espécie de fitófago ser deletéria à outra espécie sobre a mesma planta (e.g. Moran \& Whitham 1990).

Apesar de $O$. ilicis e T. urticae não interagirem diretamente por sítios de alimentação, existe ainda a possibilidade de uma espécie induzir defesas da planta capazes de reduzir a aptidão da outra espécie. Ou seja, indução de defesa direta de planta, por uma espécie de ácaro fitófago, atuaria sobre a população heteroespecífica. Ou ainda, a indução de defesa indireta de planta por uma espécie de ácaro fitófago, atuaria sobre a população de inimigos naturais que, por sua vez, seriam capazes de reduzir a densidade da população heteroespecífica.

\section{Agradecimentos}

Ao Prof. Arne Janssen pelas sugestões e correções. À Fundação de Amparo à Pesquisa do Estado de Minas Gerais (FAPEMIG) pelo financiamento do projeto de pesquisa e concessão de bolsas de estudo e produtividade científica. Ao Conselho Nacional de Desenvolvimento Científico e Tecnológico (CNPq) pela concessão das bolsas de produtividade científica.

\section{Referências}

Agrawal, A.A. 2005. Future directions in the study of induced plant responses to herbivory. Entomol. Exp. Appl. 115: 97-105.

Carey, J.R. 1993. Applied demography for biologists with special emphasis on insects. Oxford University Press, New York, $224 \mathrm{p}$.

Chiavegato, L.G. \& Mischan, M.M. 1981. Efeito de Tetranychus (T.) urticae (Koch, 1836) Boudreaux \& Dosse, 1963 (Acari, Tetranychidae) na produção do morangueiro (Fragaria $\mathrm{sp.)}$ cv. 'Campinas'. Científica 9: 257-266.

Dorn, B., L. Mattiacci, A.C. Bellotti \& S. Dorn. 2003. Effects of a mixed species infestation on the cassava mealybug and its encrytid parasitoids. Biol. Control 27: 1-10.

Foott, W.H. 1962. Competition between two species of mites. I. Experimental results. Can. Entomol. 94: 365-375.

Foott, W.H. 1963. Competition between two species of mites. II. Factors influencing intensity. Can. Entomol. 95: 45-57.

Gutierrez, J. \& W. Helle. 1985. Evolutionary changes in the Tetranychidae, p.91-107. In W. Helle \& M.W. Sabelis (eds.), Spider mites their biology, natural enemies and control. Amsterdam, Elsevier, 405p.

Hairston, N.G., F.E. Smith \& L.B. Slobodkin. 1960. Community structure, population control, and competition. Am. Nat., 94: 421-425.

Hosmer, D.W. \& S. Lemeshow. 1999. Applied survival analysis: regression modeling of time to event data. New York, Wiley, 408p.

Inbar, M., H. Doostdar \& G.L. Mayer. 1999a. Effects of sessile whitefly nymphs (Homoptera: Aleyrodidae) on leave-chewing larvae (Lepidoptera: Noctuidae). Environ. Entomol. 28: 353-357.

Inbar, M., H. Doostdar, H. Leibee \& G.L. Mayer. 1999b. The role of plant rapidly induced responses in asymmetric interespecific interactions among insect herbivores. J. Chem. Ecol. 25: 1961-1979.

Janssen, A., A. Pallini \& M. Venzon. 1998. Behaviour and indirect interactions in food webs of plant-inhabiting arthropods. Exp. Appl. Acarol. 22: 497-521.

Karban, R. \& T. Baldwin. 1997. Induced responses to herbivory. University of Chicago Press, Chicago. $317 \mathrm{p}$.

Lawton, J. \& D. Strong. 1981. Community patterns and competition in folivorous insects. Am. Nat. 118: 317-338.

Maia, A.H.N., A.J.B. Luiz \& C. Campanhola. 2000. Statistical inference on associated fertility life table parameters using Jackknife technique: computational aspects. J. Econ. Entomol. 93: 511-518.

Moran N.A. \& T.G. Whitham. 1990. Interspecific competition between root-feeding and leaf-galling aphids mediated by host-plant resistance. Ecology 71: 1050-1058.

Morris, D.W. 2003. Toward and ecological synthesis: A case for habitat selection. Oecologia 136: 1-13. 
Parrela, M.P. 1987. Biology of Liriomysa. Annu. Rev. Entomol. 32: $201-224$

Reis, P.R. \& E.B. Alves. 1997. Criação do ácaro predador Iphiseiodes zuluagai Denmark \& Muma (Acari: Phytoseiidae) em laboratório. An. Soc. Entomol. Brasil 26: 565-568.

Saitô, Y. 1983. The concept of 'life type' in Tetranychidae - An attempt to classify the spinning behaviour of Tetranychinae. Acarologia 24: 377-391.

Saitô, Y. 1985. Life types of spider mites, p.253-264. In. W. Helle \& M.W. Sabelis (eds.), Spider mites, their biology, natural enemies and control. Amsterdam, Elsevier, 405p.

Shiojiri, K, J. Takabayashi, S.Yano \& A. Takafuji. 2002. Oviposition preferences of herbivores are affected by tritrophic interaction webs. Ecol. Let. 5: 186-192.
Siegel, S. \& N.J. Castellan. 1988. Nonparametric statistics for the behavioral sciences. New York, McGraw-Hill, 395p.

Sokal, R.R. \& F.J. Rohlf. 1995. Biometry. New York, Freeman, $887 \mathrm{p}$.

van Baalen, M. \& M.W. Sabelis. 1995. The milker-killer in spatially structured predator-prey interactions. Oikos 74: 391-400. 